\title{
PENGGUNAAN MODEL PEMBELAJARAN KOOPERATIF \\ TIPE TGT (TEAMS GAMES TOURNAMENT) PADA MATA \\ PELAJARAN IPS UNTUK MENINGKATKAN HASIL BELAJAR SISWA KELAS V DI UPTD SDN BANYONENG LAOK 03 GEGER BANGKALAN
}

\author{
Joko Septaryanto ${ }^{1)}$ \\ 1) STKIP PGRI BANGKALAN
}

\begin{abstract}
ABSTRAK: Penelitian ini bertujuan untuk mengetahui aktivitas peserta didik dan hasil belajar setelah menggunakan model pembelajaran kooperatif tipe TGT (Teams Games Tournament) di kelas V UPTD SDN Banyoneng Laok 03 Geger Bangkalan. Jenis penelitian ini adalah penelitian tindakan kelas yang berkolaborasi dengan guru kelas. Subjek penelitian ini adalah siswa kelas V UPTD SDN Banyoneng Laok 03 Geger Bangkalan tahun pelajaran 2018/2019 yang terdiri dari 20 siswa, dilakukan dalam dua siklus.
\end{abstract}

Kata kunci : Model Cooperative Type TGT, Aktivitas Pembelajar, Hasil Belajar Inched.

ABSTRACT: This study aims to determine the activities of learners and learning result after using the model of cooperative learning type TGT (Teams Games Tournament) in grade V UPTD SDN Banyoneng Laok 03 Geger Bangkalan. This type of research is a classroom action research that collaboration with classroom teachers. The subject of this study were $V$ grade students UPTD SDN Banyoneng Laok 03 Geger Bangkalan year lesson 2018/2019 consisting of 20 students, conducted in two cycles.

Keywords: Model Cooperative Type TGT, Learner activity, incheased Learning Outcomes.

\section{PENDAHULUAN}

IPS sebagai salah satu bidang studi yang memiliki tujuan membekali siswa untuk mengembangkan penalarannya di samping aspek nilai dan moral, banyak memuat materi sosial dan bersifat hafalan sehingga pengetahuan dan informasi yang diterima siswa sebatas produk hafalan. Sifat materi pelajaran IPS tersebut membawa konsekuensi terhadap proses belajar mengajar yang didominasi oleh pendekatan ekspositoris (Udin S. Winataputra, 2005 : 9. 3).Pendekatan ekspositoris menitik beratkan keaktifan seorang guru dalamproses pembelajaran, sedangkan siswa cenderung pasif atau kurang terlibat, sehingga siswa tidak mempunyai kesempatan untuk mengeluarkan kemampuan yang dimiliki.Hasil belajar yang diperoleh oleh siswa kelas $\mathrm{V}$ menunjukkan bahwa hasil belajar siswa pada mata pelajaran IPS mengalami penurunan dari mata pelajaran yang lainnya, sebanyak 55\% siswa memiliki nilai dibawah KKM. Model pembelajaran yang sesuai dengan murid kelas V, yaitu model pembelajaran TGT, karena model pembelajaran ini mengandung unsur permainan yang dapat menggairahkan semangat belajar siswa, sehingga memungkinkan siswa dapat belajar lebih rileks, disamping menumbuhkan tanggung jawab, kejujuran, kerja sama, persaingan sehat dan keterlibatan belajar. Batasan 
masalah dalam penelitian ini adalah: Peneliti hanya meneliti siswa kelas V UPTD SDN Banyoneng Laok 03 Geger Bangkalan, penelitian ini difokuskan pada upaya meningkatkan hasil belajar IPS pada materi peninggalan kerajaan Hindu, Buddha dan Islam, model pembelajaran yang digunakan pada penelitian ini adalah model pembelajaran TGT. Rumusan masalah dalam penelitian ini adalah:Bagaimanakah penerapan permainan model pembelajaran TGT dapat meningkatkan hasil belajar siswa pada mata pelajaran IPS di kelas V UPTD SDN Banyoneng Laok 03 Geger Bangkalan?Dan apakah terjadi peningkatan pada hasil belajar siswa pada mata pelajaran IPSmelalui model TGT di kelas V UPTD SDN Banyoneng Laok 03 Geger Bangkalan?

Pembelajaran kooperatif model TGT adalah salah satu tipe atau model pembelajaran kooperatif yang mudah diterapkan, melibatkan seluruh siswa tanpa harus ada perbedaan status. Model pembelajaran ini melibatkan peran siswa sebagai tutor sebaya, mengandung unsur permainan yang bisa menggairahkan semangat belajar dan mengandung reinforcement. Aktivitas belajar dengan permainan yang dirancang dalam pembelajaran kooperatif model TGT memungkinkan siswa dapat belajar lebih rileks disamping menumbuhkan tanggung jawab, kejujuran, kerja sama, persaingan sehat dan keterlibatan belajar.Kelebihan Model Pembelajaran TGT yaitu:dapat mendorong dan mengkondisikan berkembangnya sikap dan keterampilan sosial siswa, meningkatkan hasil belajar, serta aktivitas siswa.Lebih meningkatkan pencurahan waktu untuk tugas.Mengedepankan penerimaan terhadap perbedaan individu.Dengan waktu yang sedikit dapat menguasai materi secara mendalam.Proses belajar mengajar berlangsung dengan keaktifan dari siswa.Mendidik siswa untuk berlatih bersosialisasi dengan orang lain.Motivasi belajar lebih tinggi.Meningkatkan kebaikan budi, kepekaan dan toleransi.Hipotesis tindakan dalam penelitian ini adalah :Dengan menggunakan modelpembelajaran kooperatif tipe Teams Games Tournament (TGT) prestasi belajar IPS siswa kelas V UPTD SDN Banyoneng Laok 03 Geger Bangkalan dapat ditingkatkan.Pada pokok bahasan peninggalan sejarah kerajaan Hindu, Buddha dan Islam dapat meningkat.

\section{METODE PENELITIAN}

Subjek penelitian ini adalah peserta didik kelas V UPTD SDN Banyoneng Laok 03 GegerBangkalan yang berjumlah 20 orang, yang terdiri dari 7 siswa laki-laki dan 13 siswi perempuan. Tempat penelitian dilaksanakan di UPTD SDN Banyoneng Laok 03 GegerBangkalan yang berlokasi di desa Banyoneng Kecamatan GegerKabupaten Bangkalan, pemilihan tempat ini dikarenakan pada sekolah tersebut peneliti menemukan fenomena atau permasalahan yang menarik untuk diteliti. Jenis penelitian ini adalah penelitian tindakan kelas (PTK), prosedur penelitian ini menggunakan model kerja yang terdiri dari empat komponen yaitu perencanaan, pelaksanaan tindakan, pengamatan 
(observasi) dan refleksi. Rancangan penelitian yang di gunakan adalah model John Elliot (dalam Yudhistira, 2012: 46) yang terdiri atas 2 siklus. Penelitian ini di fokuskan pada aktivitas belajar peserta didik, aktivitas performasi guru, dan hasil belajar peserta didik. Dengan teknik pengumpulan data berupa lembar observasi aktivitas peserta didik, lembar observasi performasi guru, soal tes tertulis bersifat tertutup yang berbentuk pilihan ganda, dan angket responden peserta didik. Dengan indikator keberhasilan tindakan sebagai berikut:jika minimal $75 \%$ siswa termotivasi dan hasil belajar meningkat di atas KKM yaitu 70 dalam pembelajaran IPS.

\section{HASIL DAN PEMBAHASAN}

\section{Hasil}

Setelah pelaksanaan tindakan menggunakan model pembelajaran kooperatif tipe TGT (Teams Games Tournament), hasil belajar peserta didik pada siklus I memperoleh nilai rata-rata 71 dengan persentase 55\% dan meningkat pada siklus II dengan nilai ratarata memperoleh 76 dengan persentase $85 \%$ berdasarkan data yang di peroleh hasil belajar peserta didik mengalami peningkatan di setiap siklusnya, hal ini menunjukkan bahwa penggunaan model pembelajaran kooperatif tipe TGT (Teams Games Tournament)dapat di gunakan dan tepat agar peserta didik aktif dalam proses pembelajaran IPS khususnya materi peninggalan kerajaan Hindu, Budha, dan Islam. Maka penelitian di hentikan karena nilai yang di peroleh sudah mencapai kriteria yang telah di tetapkan.

\section{Pembahasan}

Pembahasan hasil penelitian menggunakan model kooperatif tipe TGT (Teams Games Tournament)pada siklus I diperoleh siswa yang memperoleh nilai diatas kriteria ketuntasan minimal (KKM) sebanyak 11 orang siswa dari total 20 siswa dengan persentase $45 \%$ dengan demikian indikator keberhasilan yang di tetapkan dalam penelitian ini belum berhasil, karena itu penelitian ini dilanjutkan ke siklus II. Pada proses pembelajaran siklus II di peroleh siswa yang memperoleh nilai diatas kritrria ketuntasan minimal (KKM) sebanyak 17 orang siswa dari total 20 siswa dengan persentase $85 \%$. Maka penelitian ini dikatakan berhasil karena prestasi belajar siswa mencapai indikator pencapaian yang telah di tetapkan yaitu 70 untuk individu, dan $75 \%$ untuk klasikal.

\section{KESIMPULAN}

Penerapan model TGT pada mata pelajaran IPS materi peninggalan sejarah agama Hindu, Buddha dan Islam pada siswa kelas V UPTD SDN Banyoneng Laok 03 Geger Bangkalan sesuai dengan langkah-langkah model TGT. Hal ini dibuktikan adanya peningkatan presentase pada hasil belajar siswa, dan guru sudah merumuskan masalah, 
melakukan observasi, dan membuat kelompok belajar yang heterogen.Penerapan model TGT dapat meningkatkan hasil belajar dan prestasi siswa materi peninggalan sejarah agama Hindu, Buddha dan Islam bagi siswa kelas V UPTD SDNBanyoneng Laok 03 Geger Bangkalan. Hal ini dibuktikan adanya peningkatan presentase pada siklus I sampai siklus II. Pada siklus I ketuntasan hasil belajar siswa mencapai 45\%. Sedangkan siklus II mencapai $85 \%$.

\section{DAFTAR RUJUKAN}

Alma, Buchari, dkk. 2008. Guru Profrsional Menguasai Metode dan terampil Mengajar. Bandung: Alfabeta.

Anni, Catharina T, dkk. 2007. Psikologi Belajar. Semarang: UPT MKKUNNES.

Arikunto, Suharsimi, dkk. Penelitian Tindakan Kelas. Jakarta: BumiAksara.

Asma, Nur. 2006. Model Pembelajaran Koperatif. Jakarta: Depdiknas.

Dimyati dan Mujiono. 2009. Belajar dan Pembelajaran. Jakarta: RinekaCipta.

Ergun, Aysegul, et al. 2010. The Effect op Cooperative Learning on Eight Grade Students Achievement and Atitud Toward Science.Education Vol 131.169.

Hamalik, Oemar. 2008. Proses Belajar Mengajar. Jakarta: Bumi Aksara.

Herrhyanto, Nar dan Akib Hamid. 2008. Statistika Dasar. Jakarta: Universitas Terbuka.

Himpunan Peraturan Perundang-undangan Guru dan Dosen. 2006. Bandung: Fokusmedia.

Huda. Miftahul. 2011. Cooperative Learning Metode, Teknik, Struktur dan Model Penerapan. Yogyakarta: Pustaka Pelajar.Isjoni. 2010. Cooperative Learning.Bandung: Alfabeta. 